\title{
Effectiveness of Chinese prescription Kangen-karyu for dyslipi- demia, using 3T3-L1 adipocytes and type 2 diabetic mice
}

\author{
Chan Hum Park ${ }^{1}$, Dong Young Rhyu ${ }^{2}$, Jeong Sook Noh ${ }^{3}$, Chul Min Park ${ }^{2}$, Takako Yokozawa ${ }^{1,4, *}$ \\ ${ }^{1}$ College of Korean Medicine, Daegu Haany University, Daegu, Republic of Korea; \\ ${ }^{2}$ College of Natural Sciences and Institute of Korean Traditional Medicine Industry, Mokpo National University, Jeonnam, \\ Republic of Korea; \\ ${ }^{3}$ Department of Food Science \& Nutrition, Tongmyong University, Busan, Republic of Korea, \\ ${ }^{4}$ Graduate School of Science and Engineering for Research, University of Toyama, Toyama, Japan.
}

\begin{abstract}
Summary The Chinese prescription Kangen-karyu, comprised of six crude drugs, has received much attention due to its numerous biological activities. The present study was conducted to examine whether Kangen-karyu has an ameliorative effect on dyslipidemia. The effect of Kangen-karyu was evaluated using 3T3-L1 adipocytes, and also $d b / d b$ mice as an experimental model for diabetic dyslipidemia. Kangen-karyu significantly inhibited adipocyte differentiation and lipid accumulation. Kangen-karyu also down-regulated the mRNA levels of peroxisome proliferator-activated receptor (PPAR) $\gamma$, sterol regulatory element-binding protein (SREBP)-1c, and fatty acid synthase, and the protein levels of aP2 and PPAR $\gamma$, which indicates that Kangen-karyu inhibited adipogenesis during adipocyte differentiation, and may have potential anti-dyslipidemia effects. In addition, the administration of Kangen-karyu reduced hyperlipidemia in $d b / d b$ type 2 diabetic mice through a decline in the serum levels of lipids, and an improvement of lipoprotein profiles. The enhanced hepatic triglyceride level of the $d b / d b$ mice was significantly reduced by Kangen-karyu administration through the down-regulation of SREBP-1 and lipogenic enzymes in the liver. These findings indicate that Kangen-karyu exerts anti-dyslipidemia effects in adipocytes and type 2 diabetic $d b / d b$ mice.
\end{abstract}

Keywords: Kangen-karyu, 3T3-L1 adipocyte, $d b / d b$ mouse, dyslipidemia

\section{Introduction}

Metabolic syndrome is a multi-component disorder characterized by hypertriglyceridemia, hyperglycemia, abdominal obesity and hypertension, and is closely linked to type 2 diabetes mellitus $(1,2)$. The etiology of metabolic syndrome involves the complex interaction between genetic, metabolic, and environmental factors (3). Obesity is well recognized as the most important health problem related to the genesis of metabolic syndrome, and the rising incidence of this disease throughout the world has generated interest in the underlying mechanisms involved in these pathologies (4).

\footnotetext{
*Address correspondence to:

Dr. Takako Yokozawa, Graduate School of Science and Engineering for Research, University of Toyama, 3190 Gofuku, Toyama 930-8555, Japan.

E-mail: yokozawa@inm.u-toyama.ac.jp
}

Obesity is caused by an imbalance between energy intake and expenditure that may lead to the pathological growth of adipocytes (5). Adipocytes play a central role in regulating adipose mass and obesity. Increased adipose mass in obesity is not only caused by adipose tissue hypertrophy, but also by adipose tissue hyperplasia, which triggers the transformation of preadipocytes into adipocytes $(6,7)$. Thus, adipocyte differentiation and the amount of fat accumulation are associated with development of obesity. On the other hand, dysfunctional lipid metabolism is a key component in the development of metabolic syndrome, a very common condition characterized by dyslipidemia, insulin resistance, abdominal obesity, and hypertension, which are all related to an elevated risk of type 2 diabetes mellitus (8). The liver is an important organ for maintaining lipid metabolism and homeostasis, since it can store (via lipogenesis) or release (as lipoprotein) lipid fuels. Triglycerides (TG) are involved in the ectopic accumulation of lipid 
stores in the liver and are associated with a number of diseases, such as metabolic syndrome and type 2 diabetes.

Anti-obesity drugs such as orlistat, sibutramine, and topiramate have been used to treat obesity (9). However, these drugs have many side effects, including dry mouth, anorexia, insomnia, and gastrointestinal distress (10). Due to the adverse side effects associated with many anti-obesity drugs, recent drug trials have focused on herbal medicines (11). Under the guidelines of the US Food and Drug Administration, botanical drugs can be developed faster and more cheaply than conventional single-entity pharmaceuticals. Thus, there are many botanicals that might provide safe, natural, and cost-effective alternatives to synthetic drugs. Recent studies have found that natural bioactive compounds can be used to treat obesity in 3T3-L1 adipocytes and in an obese mouse model.

Kangen-karyu (Guan-Yuan-Ke-Li), a crude drug developed from a traditional Chinese prescription consisting of six herbs (Paeoniae Radix, Cnidii Rhizoma, Carthami Flos, Cyperi Rhizoma, Aucklandiae Radix, and Salviae Miltiorrhizae Radix), has been clinically used as a treatment for cardiovascular diseases, such as angina pectoria and cerebrovascular diseases. Kangen-karyu shows biological activity, such as an anti-aging effect, the inhibition of platelet aggregation, a hypotensive effect, and the recovery of learning and memory impairment induced by senescence (12-15). In addition, we have reported that Kangen-karyu showed favorable ameliorative effects on fructose-induced metabolic syndrome, such as hyperglycemia, hyperlipidemia, and hypertension, through the reduction of TG and cholesterol levels with the regulation of hepatic sterol regulatory element-binding protein (SREBP)-1 expression, and also exhibited protective effects against diet-induced hypercholesterolemia in rats $(16,17)$. We also reported the beneficial effect of Kangen-karyu on hyperlipidemia in streptozotocin-induced type 1 diabetic rats (18). These results suggest that Kangen-karyu can ameliorate metabolic disorders such as dyslipidemia and diabetes mellitus. Therefore, this study was designed to determine whether Kangen-karyu affects the differentiation of 3T3-L1 preadipocytes into adipocytes and the mechanism related to its differentiation. We also investigated the effect of Kangen-karyu on diabetic dyslipidemia. For this, $d b / d b$ mice were used as an experimental model for diabetic dyslipidemia. The $d b /$ $d b$ mice develop diabetes mellitus due to a failure to respond to leptin, resulting from a mutation in their receptor gene expressed in the hypothalamus, although gene expression and leptin secretion are markedly augmented in these mice, resulting in leptin resistance (19). The $d b / d b$ mice were also characterized by obesity, sustained hyperglycemia, and hyperlipidemia as a result of destroyed leptin receptors (20).

\section{Materials and Methods}

\subsection{Materials}

Dulbecco's modified Eagle's medium (DMEM), fetal calf serum (FCS), penicillin, streptomycin, and phosphate-buffered saline (PBS) were purchased from HyClone Laboratories (Logan, UT, USA). 3-(4,5-Dimethylthiazol-2-yl)-2,5-diphenyl tetrazolium bromide (MTT), insulin, dexamethasone, 3-isobutyl-1methylxanthine (IBMX), oil red O, 2-mercapthoethanol, protease inhibitor cocktail, and $\beta$-actin were purchased from Sigma-Aldrich (St Louis, MO, USA). Primary antibodies against peroxisome proliferator-activated receptor (PPAR) $\gamma, \operatorname{PPAR} \alpha$, and SREBP-1c were purchased from Santa Cruz Biotechnology (Santa Cruz, CA, USA). Similarly, secondary antibodies for mouse (peroxidase-conjugated affinipure goat anti-mouse $\mathrm{IgG}$ ) and rabbit (peroxidase-conjugated affinipure goat anti-rabbit $\mathrm{IgG}$ ) were purchased from Jackson ImmunoResearch Laboratories (Baltimore, USA). The protein molecular weight marker was obtained from Thermo Scientific (Rockford, IL, USA). The nitrocellulose membrane for Western blotting was purchased from Bio-Rad Laboratories (Richmond, CA, USA). Western blot chemiluminescent substrate was purchased from Imgenex (San Diego, CA, USA). Radioimmunoprecipitation assay buffer was purchased from Biosesang (Seoul, Korea). ECL Western Blotting Detection Reagents were purchased from GE Health Care (Piscataway, NJ, USA). All solvents, chemicals, and reagents were of analytical grade and purchased from Sigma-Aldrich unless otherwise specified.

\subsection{Preparation of Kangen-karyu extract}

The composition of Kangen-karyu used in this study is shown in Table 1. Kangen-karyu was as follows (values indicate proportions of each ingredient, expressed in parts per whole): Paeoniae Radix 2, Cnidii Rhizoma 2, Carthami Flos 2, Cyperi Rhizoma 1, Aucklandiae Radix 1, Salviae Miltiorrhizae Radix 4. These six crude drugs were boiled gently in 25 times their volume of water at $100^{\circ} \mathrm{C}$ for $1 \mathrm{~h}$. After filtration, the solution was evaporated under reduced pressure to give an extract at a yield of $44 \%$, by weight, of the

\section{Table 1. Composition of Kangen-karyu}

\begin{tabular}{lll}
\hline Common name & Botanical name & Family name \\
\hline Paeoniae Radix & Paeonia lactiflora PALLAS & Paeoniaceae \\
Cnidii Rhizoma & Cnidium officinale MAKINO & Umbelliferae \\
Carthami Flos & Carthamus tinctorius L. & Compositae \\
Cyperi Rhizoma & Cyperus rotundus L. & Cyperaceae \\
Aucklandiae Radix & Aucklandia lappa DCNE. & Compositae \\
Salviae Miltiorrhizae & Salvia miltiorrhiza BUNGE & Labiatae \\
Radix & & \\
\hline
\end{tabular}


starting materials. The extract was dissolved in $50 \%$ aqueous ethanol with sonication, and filtered through a Cosmonice filter (PVDF, $0.45 \mu \mathrm{m}$; Nakalai Tesque, Kyoto, Japan). Reverse-phase high-performance liquid chromatography was performed using a Cosmosil $5 \mathrm{C}_{18^{-}}$ AR II column $(250 \times 4.6 \mathrm{~mm}$ i.d.; Nakalai Tesque $)$ with elution gradients of $4-30 \%$ (39 $\mathrm{min}$ ) and $30-75 \%$ (15 min) $\mathrm{CH}_{3} \mathrm{CN}$ in $50 \mathrm{mM} \mathrm{H}_{3} \mathrm{PO}_{4}$ at a flow rate of $0.8 \mathrm{~mL} / \mathrm{min}$. The UV absorbance from 200 to $400 \mathrm{~nm}$ was monitored with a Jasco MD-910 photodiode array detector (Jasco, Tokyo, Japan). All assigned peaks were identified by carrying out co-injection tests with authentic samples and comparing with UV spectral data. The major compounds detected were paeoniflorin, pentagalloyl glucose, rosmarinic acid, lithospermic acid, and lithospermic acid B. A voucher specimen has been deposited in the herbarium of the University of Toyama.

\subsection{Culture cell experiments}

\subsubsection{Cell culture and differentiation}

3T3-L1 preadipocytes obtained from the American Type Culture Collection (Manassas, VA, USA) were cultured in DMEM containing 10\% FCS, $100 \mu \mathrm{g} / \mathrm{mL}$ streptomycin, $100 \mathrm{U} / \mathrm{mL}$ penicillin, $44 \mathrm{mM} \mathrm{NaHCO}$, and $1 \mathrm{mM}$ sodium pyruvate at $37^{\circ} \mathrm{C}$ under a $5 \% \mathrm{CO}_{2}$ atmosphere. To induce differentiation, 3T3-L1 preadipocytes were cultured until confluence was reached (day 0), and the culture medium was replaced with a fresh induction medium containing $5 \mu \mathrm{g} / \mathrm{mL}$ insulin, $0.5 \mathrm{mM}$ IBMX, and $1 \mu \mathrm{M}$ dexamethasone in DMEM with $10 \%$ FCS for 2 days. The medium was then replaced with a differentiation medium containing $5 \mu \mathrm{g} / \mathrm{mL}$ insulin only and DMEM medium containing 10\% FCS every 2 days for 8 days until the cells were harvested. To examine the effect of Kangen-karyu on adipogenesis, the extract was dissolved in the differentiation medium, and the medium was immediately processed into a sterile container by membrane filtration with a $0.22-\mu \mathrm{m}$ filter (EMD Millipore, MA, USA).

\subsubsection{MTT assay}

3T3-L1 preadipocytes were seeded at a density of $4 \times 10^{3}$ cells/well in a 96-well plate. After $4 \mathrm{~h}$, Kangen-karyu extract at concentrations of 25, 50, 125 , and $250 \mu \mathrm{g} / \mathrm{mL}$ was added to each well and incubated for $24 \mathrm{~h}$. MTT solution ( $2 \mathrm{mg} / \mathrm{mL}$ ) was added to each 96-well plate and incubated for $4 \mathrm{~h}$, and then the medium containing MTT solution was removed. The formazan crystals in the viable cells were solubilized with dimethyl sulfoxide $(150 \mu \mathrm{L})$, and absorbance was determined at $540 \mathrm{~nm}$ with a Microplate Reader (Immuno Mini NJ-2300; BioTec, Tokyo, Japan).

\subsubsection{Oil red O staining}

Intracellular lipid accumulation was measured using oil red $\mathrm{O}$ staining. The mature 3T3-L1 adipocytes were washed with PBS, fixed with $10 \%$ formalin $(\mathrm{pH}$ 7.4) for $30 \mathrm{~min}$, and stained with oil red $\mathrm{O}$ solution for $1 \mathrm{~h}$. The fat droplets in 3T3-L1 adipocytes were observed by phase contrast microscopy.

\subsubsection{Western blot analysis}

3T3-L1 adipocytes, cultured in 6-well plates, were treated with Kangen-karyu extract for 8 days and harvested using PRO-PREP ${ }^{\mathrm{TM}}$ protein extraction solution (iNtRON Biotechnology, Seoul, Korea). Cell debris was removed by centrifugation and the protein quantity in the lysate was determined using Bradford reagent (Bio-Rad Laboratories, Hercules, CA, USA). Cell lysates containing $30 \mu \mathrm{g}$ of protein were separated using sodium dodecylsulfate polyacrylamide gel (SDSPAGE) electrophoresis and transferred to nitrocellulose membranes, and the membranes were blocked with a solution of $0.1 \%$ Tween 20 in Tris-buffered saline containing 5\% skim milk for $1 \mathrm{~h}$ at room temperature followed by overnight incubation with primary antibody at $4^{\circ} \mathrm{C}$. After overnight incubation, the membranes were incubated with horseradish peroxidase-conjugated secondary antibody for $1 \mathrm{~h}$ at room temperature. Finally, protein bands were detected using the chemiluminescent substrate and VisionWorks ${ }^{\mathrm{TM}} \mathrm{LS}$ (Analysis Software, Upland, CA, USA).

\subsubsection{Quantitative real-time polymerase chain reaction (PCR)}

Total RNA was isolated from cells using Tri Reagent (Molecular Research Center, Cincinnati, OH, USA) and quantified using NanoDrop (Thermo Scientific, Wilmington, DE, USA). Fifty ng of isolated RNA was added to a final $30-\mu 1$ volume of the Diastar ${ }^{\mathrm{TM}}$ 2X One Step RT-PCR kit (SolGent, Daejeon, Korea) with each primer: PPAR $\gamma$, forward sequence 5'-ACC ACT CGC ATT CCT TTG AC-3', reverse sequence 5'TCA GCG GGA AGG ACT TTA TG-3'; SREBP-1c, forward sequence 5'-CAC TTC TGG AGA CAT CGC AAA C-3', reverse sequence 5'-TGG TAG ACA ACA GCC GCA TC-3'; fatty acid synthase (FAS), forward sequence 5'-CTG CGG AAA CTT CAG GAA ATG-3', reverse sequence 5'-GGT TGC TCG GAA TAT CCA GG-3'. The temperature cycle for the PCR reaction was $50^{\circ} \mathrm{C}$ for $30 \mathrm{~min}, 95^{\circ} \mathrm{C}$ for $15 \mathrm{~min}$, and 30 cycles of [denaturation at $95^{\circ} \mathrm{C} \times 1 \mathrm{~min}$, annealing at $58^{\circ} \mathrm{C}$ (PPAR $\gamma$, SREBP-1c, and $\beta$-actin) and $55^{\circ} \mathrm{C}(\mathrm{FAS}) \times$ $1 \mathrm{~min}$ and extension at $72^{\circ} \mathrm{C}$ for $1 \mathrm{~min}$ ] followed by final denaturation at $72^{\circ} \mathrm{C}$ for $5 \mathrm{~min}$. $\beta$-Actin of the forward sequence 5'-TGC CCA TCT ATG AGG GTT ACG-3', reverse sequence 5'-TAG AAG CAT TTG 
CGG TGC ACG-3', and the reaction cycle was as mentioned above. The obtained PCR products were analyzed in nucleic acid staining solution (Red Safe, iNtRON, Korea)-stained agarose (1.5\%) gel by using VisionWorks ${ }^{\mathrm{TM}}$ LS UVP (Analysis Software, Upland, CA, USA).

\subsection{Animal experiments}

\subsubsection{Experimental animals and treatment}

The 'Guidelines for Animal Experimentation' approved by the University of Toyama were followed in the present study (Registration No.: S-2006 INM-22). Male, 5-wk-old, C57BLKS/J $d b / d b$ mice and their agematched, non-diabetic $m / m$ littermates were purchased from Japan SLC (Hamamatsu, Japan). They were kept in a plastic-bottomed cage and exposed to a 12-h light/dark cycle. Room temperature (about $25^{\circ} \mathrm{C}$ ) and humidity (about $60 \%$ ) were controlled automatically. The mice were allowed free access to laboratory pellet chow (CLEA Japan, Tokyo, Japan, comprising 24.0\% protein, $3.5 \%$ lipids, and $60.5 \%$ carbohydrate) and water was given ad libitum. After adaptation, glucose and TG levels of blood taken from the tail vein were measured, and then $d b / d b$ mice were divided into three groups. The treatment with Kangen-karyu was initiated after confirming the induction of hyperglycemia and hyperlipidemia in the $d b / d b$ mice, based on the presence of serum glucose $300 \pm 10 \mathrm{mg} / \mathrm{dL}$ and serum TG $160 \pm$ $5 \mathrm{mg} / \mathrm{dL}$, respectively. The $d b / d b$ vehicle group $(n=8)$ was orally given water, while the other two groups $(n$ $=8$ per group) were orally administered Kangen-karyu extract every day for 18 weeks at a dose of $100 \mathrm{mg}$ or $200 \mathrm{mg} / \mathrm{kg}$ body weight, respectively. The non-diabetic $m / m$ mice $(n=6)$ as a normal group were compared with the diabetic groups. When the $d b / d b$ mice reached 24 weeks old, they showed reduced blood glucose, $\beta$-cell necrosis, and diminished hyperinsulinemia (21). Therefore, we decided on the time-point for the cessation of treatment as 24 weeks old in $d b / d b$ mice. Food and water intakes were determined every day during the experimental period. After administration for 18 weeks, blood samples were collected by cardiac puncture from anesthetized mice. Serum was separated immediately by centrifugation. Subsequently, each mouse was perfused with ice-cold physiological saline, and then the liver was harvested, snap-frozen in liquid nitrogen, and stored at $-80^{\circ} \mathrm{C}$ until analyses.

\subsubsection{Measurement of serum parameters}

Glucose, TG, total cholesterol, and non-esterified fatty acids (NEFA) were measured using a commercial kit (Glucose CII-Test, Triglyceride E-Test, Cholesterol E-Test, and NEFA C-Test from Wako Pure Chemical Industries, Osaka, Japan). Leptin and insulin (Morinaga
Institute of Biological Science, Yokohama, Japan) levels were measured based on enzyme-linked immunosorbent assays. High-density lipoprotein (HDL), low-density lipoprotein (LDL), and very low-density lipoprotein (VLDL) cholesterol distributions were measured using a BioVision kit (BioVision, Mountain View, CA, USA). Alanine aminotransferase (ALT) and aspartate aminotransferase (AST) were determined using a commercial reagent: GPT-UV Test Wako (Wako Pure Chemical Industries).

\subsubsection{Measurement of hepatic TG content}

The liver of each mouse was homogenized and total lipids of the liver homogenates were extracted with a mixture of chloroform and methanol $(2: 1, \mathrm{v} / \mathrm{v})$ according to the method of Folch et al. (22). Then, the amount of TG was determined using commercial kits, as described previously.

\subsubsection{Preparation of nuclear fraction}

To prepare nuclear fractions, hepatic tissues were homogenized with ice-cold lysis buffer containing 5 $\mathrm{mM}$ Tris-HCl (pH 7.5), $2 \mathrm{mM} \mathrm{MgCl}, 15 \mathrm{mM} \mathrm{CaCl}_{2}$, and $1.5 \mathrm{M}$ sucrose, and then $0.1 \mathrm{M}$ dithiothreitol (DTT) and protease inhibitor cocktail were added. After centrifugation $\left(10,500 \times \mathrm{g}\right.$ for $20 \mathrm{~min}$ at $\left.4^{\circ} \mathrm{C}\right)$, the pellet was suspended with extraction buffer containing 20 $\mathrm{mM}$ 2-[4-(2-hydroxyethyl)-1-piperazyl] ethanesulfonic acid (pH 7.9), $1.5 \mathrm{mM} \mathrm{MgCl}, 0.42 \mathrm{M} \mathrm{NaCl}, 0.2 \mathrm{mM}$ EDTA, and 25\% (v/v) glycerol, and then 0.1 M DTT and protease inhibitor cocktail were added. The mixture was placed on ice for $30 \mathrm{~min}$. The nuclear fraction was prepared by centrifugation at $20,500 \times \mathrm{g}$ for $5 \mathrm{~min}$ at $4^{\circ} \mathrm{C}$. The protein concentration was determined using a commercial kit (Bio-Rad Laboratories, Hercules, CA, USA).

\subsubsection{Western blot analyses}

For the determination of PPAR $\alpha$ and SREBP-1, $10 \mu \mathrm{g}$ of protein of each nuclear fraction was electrophoresed through $8 \%$ SDS-PAGE. Separated proteins were transferred to a nitrocellulose membrane, blocked with $5 \%(\mathrm{w} / \mathrm{v})$ skim milk solution for $1 \mathrm{~h}$, and then incubated with primary antibodies to PPAR $\alpha$, SREBP-1, and histone, respectively, overnight at $4^{\circ} \mathrm{C}$. After the blots were washed, they were incubated with anti-rabbit or anti-mouse IgG horseradish peroxidase-conjugated secondary antibody for $1.5 \mathrm{~h}$ at room temperature. Each antigen-antibody complex was visualized using ECL Western Blotting Detection Reagents and detected by chemiluminescence with LAS-4000 (Fujifilm, Tokyo, Japan). Band densities were determined using ATTO Densitograph Software (ATTO Corporation, Tokyo, Japan) and quantified as the ratio to histone. These 
protein levels of groups are expressed relative to those of $\mathrm{m} / \mathrm{m}$ mice (represented as 1).

\subsection{6. $P C R$}

Total RNA was isolated from hepatic tissue using Trizol reagent (Invitrogen Life Technologies, Carlsbad, CA, USA) and quantified using NanoDrop (Thermo Scientific, Wilmington, DE, USA). The cDNAs were synthesized from $5 \mathrm{mg}$ of RNA employing reverse transcriptase (Qiagen, Tokyo, Japan). For the realtime PCR, triplicate aliquots of serially diluted cDNA samples were used in a reaction mixture that contained $1 \mathrm{mM}$ of each primer in a reaction volume of $50 \mathrm{~mL}$ employing the SYBR Green Real-time PCR kit (Qiagen) using a fluorometric thermal cycler (Mx3000P ${ }^{\mathrm{TM}}$; Stratagene, La Jolla, CA, USA). Reaction mixtures were incubated for an initial denaturation at $95^{\circ} \mathrm{C}$ for $15 \mathrm{~min}$, followed by 45 cycles of $94^{\circ} \mathrm{C}$ for $15 \mathrm{~s}, 60^{\circ} \mathrm{C}$ for $30 \mathrm{~s}$, and $72^{\circ} \mathrm{C}$ for $30 \mathrm{~s}$. Primers used were as follows: acetyl-CoA carboxylase (ACC, sense: CCCAGCAGAATAAAGCTACTTTGG, antisense: TCCTTTTGTGCAACTAGGAACGT), FAS (sense: CCTGGATAGCATTCCGAACCT, antisense: AGCACATCTCGAAGGCTACACA). Glyceraldehyde-3-phosphate dehydrogenase (GAPDH) was used as an endogenous control. The $\mathrm{DC}_{\mathrm{T}}$ method was employed for relative quantification. The $\mathrm{DC}_{\mathrm{T}}$ value for each sample was determined by calculating the difference between the $\mathrm{C}_{\mathrm{T}}$ value of the target gene and that of the GAPDH reference gene. The normalized target gene expression level in the sample was calculated using the formula $2^{-\mathrm{DDCT}}$ as the fold change over the control.

\subsection{Statistical analysis}

Data are expressed as mean values with their standard errors. Statistical comparisons were performed by oneway ANOVA followed by Duncan's multiple-range test. Statistical analysis was conducted using SAS (release 9.2; SAS Institute, Cary, NC, USA) and $p<0.05$ was considered significant.

\section{Results}

\subsection{Culture cell experiments}

\subsubsection{Cell viability}

To test the cytotoxic effects, MTT assays were conducted after treatment with various concentrations of Kangen-karyu during the adipogenesis of 3T3L1 cells. The results of the MTT assay showed that Kangen-karyu did not decrease the cell viability up to the concentration of $250 \mu \mathrm{g} / \mathrm{mL}$, as shown in Figure 1 . Orlistat, which inhibits the absorption of neutral lipids and cholesterol by specifically inhibiting lipase (23), at a concentration of $20 \mu \mathrm{M}(10 \mu \mathrm{g} / \mathrm{mL})$ did not affect the cell viability.

\subsubsection{Lipid accumulation}

As shown in Figure 2A, Kangen-karyu significantly inhibited the accumulation of lipid droplets at a concentration of 50 and $250 \mu \mathrm{g} / \mathrm{mL}$. As the main components of fat droplets are lipids in the form of TG, the TG contents of cells were determined. As shown in Figure 2B, Kangen-karyu reduced TG accumulation. When the 3T3-L1 cells were treated with orlistat, TG accumulation was reduced by $36 \%$ at a concentration of $20 \mu \mathrm{M}$.

\subsubsection{PPAR $\gamma$ and aP2 protein expressions}

As shown in Figure 3, the levels of PPAR $\gamma$ (A) and aP2 (B) were significantly inhibited by treatment with both

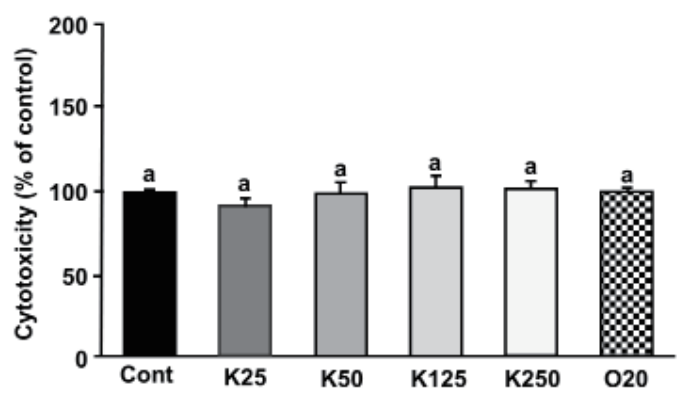

Figure 1. Cell viability. Cont, control; K25, Kangen-karyu 25 $\mu \mathrm{g} / \mathrm{mL}$; K50, Kangen-karyu $50 \mu \mathrm{g} / \mathrm{mL}$; K125, Kangen-karyu $125 \mu \mathrm{g} / \mathrm{mL}$; K250, Kangen-karyu $250 \mu \mathrm{g} / \mathrm{mL}$; O20, orlistat 20 $\mu \mathrm{M}$. Data are the mean \pm S.E.M. Bars with the same letter are not significantly different by Duncan's multiple range tests $(p$ $<0.05)$.

(A)

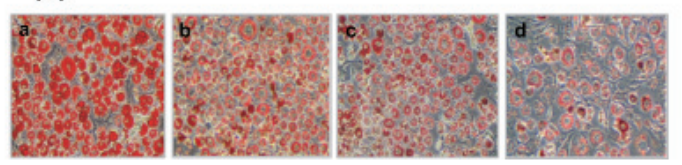

(B)

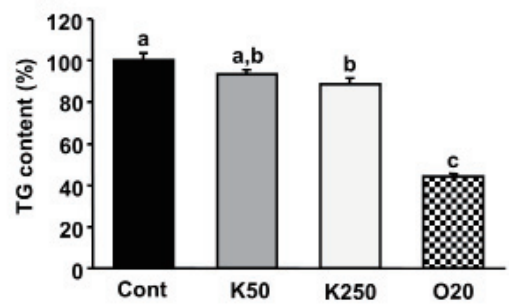

Figure 2. Lipid accumulation in 3T3-L1 adipocytes. Confluent cells were treated with Kangen-karyu or orlistat. (A) Cell differentiation was examined on day 8 by oil red $\mathrm{O}$ staining. (B) The TG content was measured in 3T3-L1 adipocytes. Cont, control; K50, Kangen-karyu 50 нg/mL; K250, Kangen-karyu 250 $\mu \mathrm{g} / \mathrm{mL}$; O20, orlistat $20 \mu \mathrm{M}$. Data are the mean \pm S.E.M. Bars with the same letter are not significantly different by Duncan's multiple range tests $(p<0.05)$. 
50 and $250 \mu \mathrm{g} / \mathrm{mL}$ Kangen-karyu. The effects of Kangenkaryu on PPAR $\gamma$ were more prominent than those of aP2.

\subsubsection{PPAR , SREBP-1c, and FAS mRNA expressions}

The treatment with Kangen-karyu at $250 \mu \mathrm{g} / \mathrm{mL}$ led to

(A)

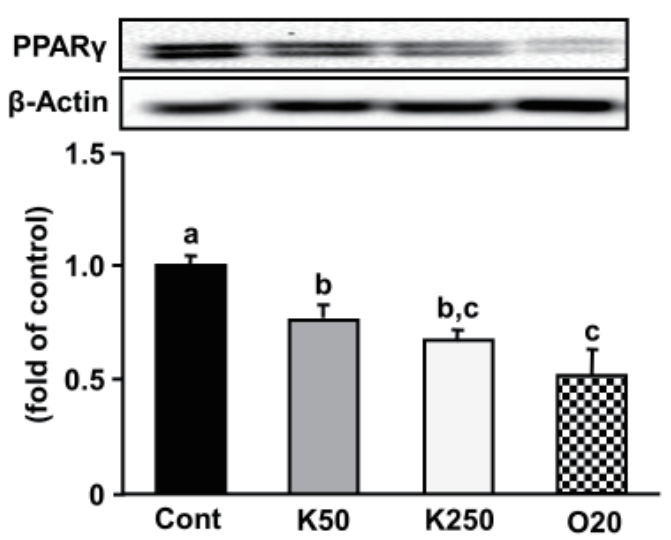

(B)

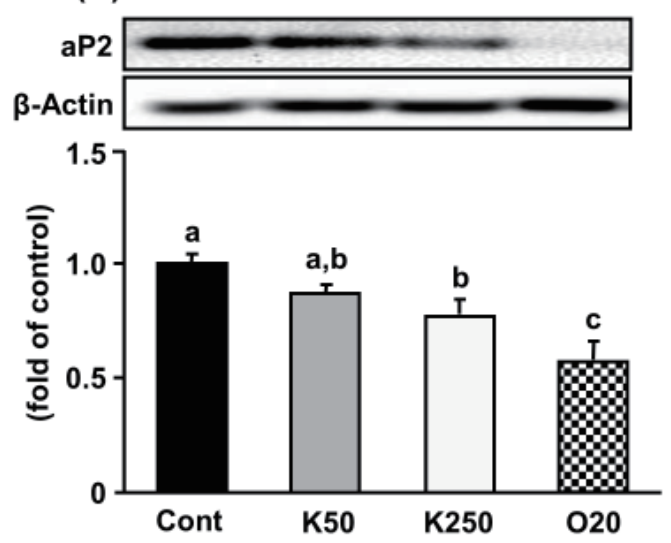

Figure 3. PPAR $\gamma$ and aP2 protein expressions in 3T3-L1 adipocytes. Representative immunoblots for (A) PPAR $\gamma$ and (B) aP2. Immunoblotting analyses were performed as described in Materials and Methods. Cont, control; K50, Kangen-karyu 50 $\mu \mathrm{g} / \mathrm{mL}$; K250, Kangen-karyu $250 \mu \mathrm{g} / \mathrm{mL}$; O20, orlistat $20 \mu \mathrm{M}$. Data are the mean \pm S.E.M. Bars with the same letter are not significantly different by Duncan's multiple range tests $(p<0.05)$. a significant inhibition of PPAR $\gamma$, SREBP-1c, and FAS mRNA expressions, as shown in Figure 4. In particular, the effect of PPAR $\gamma$ was marked and distinct from those of the other mRNA expressions.

\subsection{Animal experiments}

\subsubsection{Body weight, food intake, and water intake}

The $d b / d b$ mice displayed typical phenotypes of obesity-induced diabetes with a marked increase in body weight gain, food intake, and water intake, as compared with $\mathrm{m} / \mathrm{m}$ mice (normal control). The gain of body weight in $d b / d b$ mice was non-significantly decreased by Kangen-karyu administration. The food and water intakes in $d b / d b$ mice were significantly decreased by $100 \mathrm{mg} / \mathrm{kg}$ of Kangen-karyu treatment.

\subsubsection{Hematological analyses}

All serum constituents were elevated in vehicle-treated $d b / d b$ mice compared with $\mathrm{m} / \mathrm{m}$ mice. As shown in Table 2, Kangen-karyu $200 \mathrm{mg} / \mathrm{kg}$-administered $d b /$ $d b$ mice groups showed decreased serum glucose and leptin, but no alteration of insulin. Furthermore, the administration of Kangen-karyu to $d b / d b$ mice significantly improved TG, LDL/VLDL cholesterol, and NEFA compared with the $d b / d b$ control group. Regarding hepatic function parameters, serum ALT and AST levels in vehicle $d b / d b$ mice were elevated compared with those in $\mathrm{m} / \mathrm{m}$ mice, while, in Kangenkaryu-administered $d b / d b$ mice, these two parameters were slightly decreased.

\subsubsection{Hepatic TG content}

Compared with $\mathrm{m} / \mathrm{m}$ mice, the liver weight of $\mathrm{db}$ / $d b$ mice was significantly augmented, but the administration of Kangen-karyu led to a significant decrease in its weight. Concerning the hepatic content of $\mathrm{TG}$, the $d b / d b$ control group showed a marked increase compared with the $\mathrm{m} / \mathrm{m}$ group. This TG
(A)
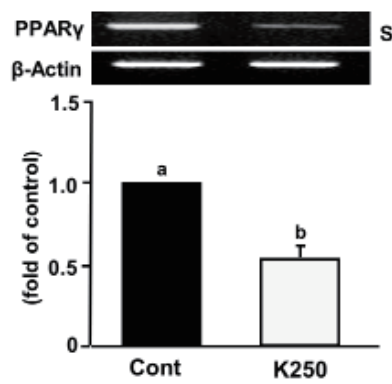

(B)
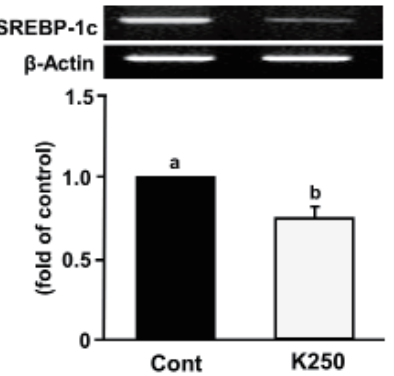

(C)

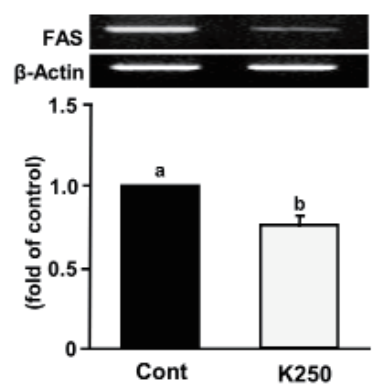

Figure 4. PPAR $\gamma$, SREBP-1c, and FAS mRNA expressions in 3T3-L1 adipocytes. Representative immunoblots for (A) PPAR $\gamma$, (B) SREBP-1c, and (C) FAS. Immunoblotting analyses were performed as described in Materials and Methods. Cont, control; K250, Kangen-karyu $250 \mu \mathrm{g} / \mathrm{mL}$. Data are the mean \pm S.E.M. Bars with the same letter are not significantly different by Duncan's multiple range tests $(p<0.05)$. 
Table 2. Hematological analyses

\begin{tabular}{|c|c|c|c|c|}
\hline \multirow{2}{*}{ Item } & \multirow{2}{*}{$\mathrm{m} / \mathrm{m}$} & \multicolumn{3}{|c|}{$d b / d b$} \\
\hline & & Veh & K100 & K200 \\
\hline Glucose (mg/dL) & $134 \pm 5^{* * *}$ & $492 \pm 13$ & $434 \pm 30$ & $420 \pm 17^{*}$ \\
\hline Leptin (ng/mL) & $1.8 \pm 0.1 * * *$ & $21.0 \pm 0.8$ & $18.7 \pm 1.2$ & $15.8 \pm 0.5 * * *$ \\
\hline Insulin (ng/mL) & $1.57 \pm 0.03 * * *$ & $3.36 \pm 0.17$ & $3.85 \pm 0.30$ & $4.24 \pm 0.74$ \\
\hline TG (mg/dL) & $117 \pm 15^{* * *}$ & $212 \pm 12$ & $135 \pm 18^{* *}$ & $104 \pm 14 * * *$ \\
\hline Total cholesterol (mg/dL) & $78 \pm 1 * * *$ & $162 \pm 8$ & $159 \pm 13$ & $155 \pm 15$ \\
\hline HDL-C (mg/dL) & $42.3 \pm 2.9^{*}$ & $52.0 \pm 2.8$ & $52.4 \pm 1.6$ & $53.7 \pm 4.0$ \\
\hline LDL / VLDL-C (mg/dL) & $9.1 \pm 0.3 * * *$ & $20.1 \pm 1.3$ & $12.0 \pm 1.1 * * *$ & $10.8 \pm 1.0^{* * *}$ \\
\hline $\mathrm{NEFA}(\mathrm{mEq} / \mathrm{L})$ & $0.58 \pm 0.02 * * *$ & $1.38 \pm 0.08$ & $1.05 \pm 0.06$ & $1.00 \pm 0.05^{*}$ \\
\hline $\operatorname{ALT}(\mathrm{IU} / \mathrm{L})$ & $35 \pm 2 * *$ & $98 \pm 16$ & $89 \pm 8$ & $85 \pm 17$ \\
\hline AST (IU/L) & $11 \pm 3 * * *$ & $61 \pm 4$ & $55 \pm 7$ & $53 \pm 4$ \\
\hline
\end{tabular}

$m / m$, Misty mice; $d b / d b$-Veh, $d b / d b$ vehicle-treated mice; $d b / d b$-K100, $d b / d b$ Kangen-karyu (100 mg/kg body weight)-treated mice; $d b / d b$-K200, $d b / d b$ Kangen-karyu (200 mg/kg body weight)-treated mice. Data are the mean \pm S.E.M. Significance: ${ }^{*} p<0.05, * * p<0.01, * * * p<0.001 v s$. vehicle-treated $d b / d b$ group.

Table 3. Liver weight and TG level

\begin{tabular}{|c|c|c|c|c|}
\hline \multirow{2}{*}{ Item } & \multirow{2}{*}{$\mathrm{m} / \mathrm{m}$} & \multicolumn{3}{|c|}{$d b / d b$} \\
\hline & & Veh & K100 & $\mathrm{K} 200$ \\
\hline Liver weight (g) & $1.44 \pm 0.21 * * *$ & $4.11 \pm 0.19$ & $3.73 \pm 0.16$ & $3.14 \pm 0.61$ \\
\hline Liver weight (g/100 g body weight) & $5.58 \pm 0.41^{* *}$ & $7.89 \pm 0.41$ & $7.03 \pm 0.35$ & $5.87 \pm 1.14$ \\
\hline TG (mg/g tissue) & $3.1 \pm 0.2 * * *$ & $18.7 \pm 1.2$ & $15.3 \pm 0.7^{*}$ & $13.4 \pm 0.9^{* *}$ \\
\hline
\end{tabular}

$m / m$, Misty mice; $d b / d b$-Veh, $d b / d b$ vehicle-treated mice; $d b / d b$-K100, $d b / d b$ Kangen-karyu (100 mg/kg body weight)-treated mice; $d b / d b-\mathrm{K} 200$, $d b / d b$ Kangen-karyu (200 mg/kg body weight)-treated mice. Data are the mean \pm S.E.M. Significance: ${ }^{*} p<0.05, * * p<0.01, * * * p<0.001 v s$. vehicle-treated $d b / d b$ group.

content was significantly decreased by Kangen-karyu administration at a dose of 100 and $200 \mathrm{mg} / \mathrm{kg}$ body weight/day, as shown in Table 3.

\subsubsection{Hepatic PPAR a and SREBP-1 protein expressions}

As shown in Figure 5B, protein expression of hepatic SREBP-1 was markedly increased in the $d b / d b$ control group compared with the $\mathrm{m} / \mathrm{m}$ group. The administration of Kangen-karyu at 100 and $200 \mathrm{mg} /$ $\mathrm{kg}$ led to a significant down-regulation of SREBP-1 expression. While, in the case of hepatic PPAR $\alpha$, no significant difference among the groups was observed (Figure 5A).

\subsubsection{Hepatic mRNA expressions involved in TG metabolism}

The effects of Kangen-karyu administration on the mRNA levels of genes involved in lipid metabolism in the hepatic tissue are presented in Figure 6. Overexpressions of ACC and FAS mRNA were seen in hepatic tissue of the $d b / d b$ vehicle group compared with $\mathrm{m} / \mathrm{m}$ group. On the other hand, the administration of Kangen-karyu at a dose of $200 \mathrm{mg} / \mathrm{kg}$ body weight/day significantly inhibited the expressions of ACC and FAS in $d b / d b$ mice.

\section{Discussion}

Dysregulation of the pathways involved in adipogenesis, lipid metabolism, and energy homeostasis can lead to the development of obesity, hepatic steatosis, diabetes, and dyslipidemia. The transcription factors PPAR $\gamma$ and CCAAT/enhancer-binding protein- $\alpha$ $(\mathrm{C} / \mathrm{EBP} \alpha)$ play a crucial role during adipogenesis. In the later stages of terminal differentiation, proteins such as adipocyte-specific fatty acid-binding protein (aP2), adiponectin, and leptin are expressed. A fine balance between adipocyte hypertrophy and adipogenesis exists to prevent the formation of dysfunctional adipose tissue, since large cells are more likely to be insulin-resistant and, therefore, can influence adipose tissue metabolism.

Adipose tissue, as a metabolic and endocrine organ, plays critical roles in the regulation of energy balance, lipid metabolism, and insulin action. Obesity is a major public health problem involving increased risks of diabetes and cardiovascular disease in many countries. Adipocytes have been emerging as a potential pharmacological target for obesity, diabetes, and cardiovascular diseases (24-26). Numerous studies have demonstrated that adipocyte differentiation and the amount of fat accumulation are associated with the occurrence and development of obesity. The findings of this study show that Kangen-karyu plays 
(A)

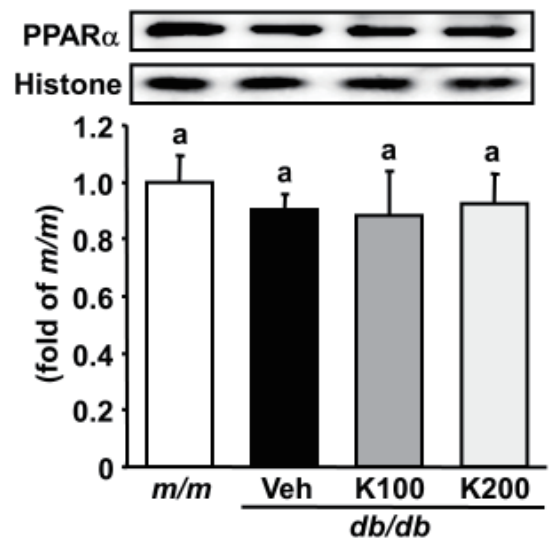

(B)
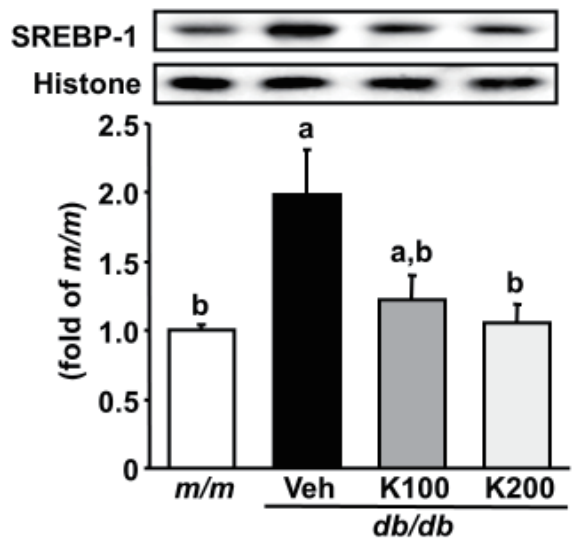

Figure 5. PPARa and SREBP-1 protein expressions in the liver. Representative immunoblots for (A) PPAR $\alpha$ and (B) SREBP-1. Immunoblotting analyses were performed as described in Materials and Methods. $m / m$, Misty mice; $d b / d b$-Veh, $d b / d b$ vehicle-treated mice; $d b / d b-\mathrm{K} 100, d b / d b$ Kangen-karyu (100 mg/ kg body weight)-treated mice; $d b / d b-K 200, d b / d b$ Kangen-karyu (200 mg/kg body weight)-treated mice. Data are the mean \pm S.E.M. Bars with the same letter are not significantly different by Duncan's multiple range tests $(p<0.05)$.

a significant role in the regulation of energy and lipid metabolism. Our results show that Kangen-karyu significantly inhibited adipocyte differentiation and lipid accumulation. Kangen-karyu significantly reduced TG accumulation, which indicates that it inhibited adipogenesis during adipocyte differentiation, and may have potential anti-dyslipidemia effects.

The differentiation of preadipocytes into adipocytes is regulated by the coordinated expression of various transcription factors, and the induction of metabolic pathways related to lipid metabolism induces the expression of several adipocyte-specific genes like PPAR $\gamma$, SREBP-1c, and FAS (27). In addition, lipid homeostasis is regulated by a family of membranebound transcription factors called SREBPs (28). SREBP-1 is a key transcription factor that nutritionally regulates the hepatic gene expression of lipogenic enzymes and TG deposition in the liver (29). In the present study, Kangen-karyu significantly downregulated the mRNA levels of PPAR $\gamma$, SREBP-1c, and

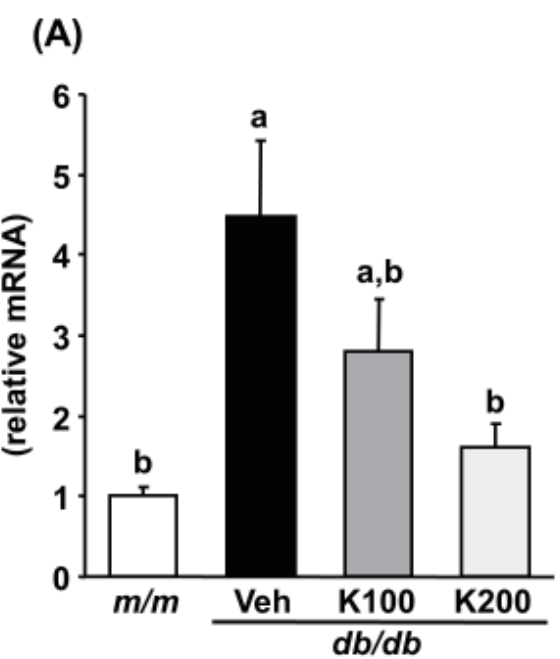

(B)

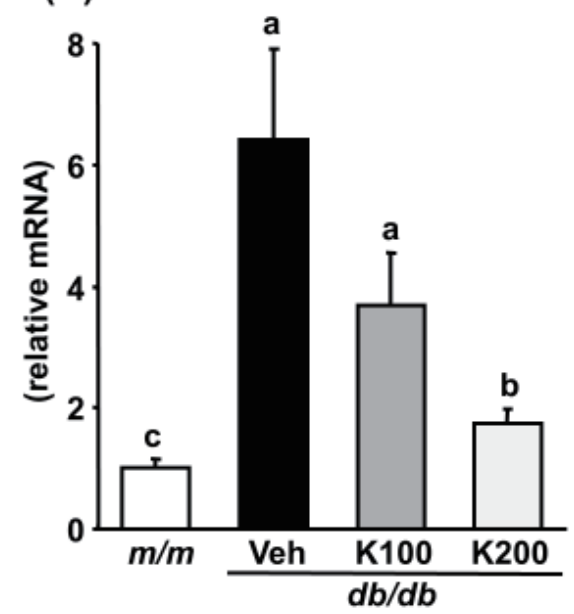

Figure 6. ACC and FAS mRNA expressions in the liver. Representative immunoblots for (A) ACC and (B) FAS. Immunoblotting analyses were performed as described in Materials and Methods. $m / m$, Misty mice; $d b / d b$-Veh, $d b / d b$ vehicle-treated mice; $d b / d b-K 100, d b / d b$ Kangen-karyu (100 $\mathrm{mg} / \mathrm{kg}$ body weight)-treated mice; $d b / d b-\mathrm{K} 200, d b / d b$ Kangenkaryu $(200 \mathrm{mg} / \mathrm{kg}$ body weight)-treated mice. Data are the mean \pm S.E.M. Bars with the same letter are not significantly different by Duncan's multiple range tests $(p<0.05)$.

FAS, and the protein levels of aP2 and PPAR $\gamma$ in mature adipocytes. These results suggest that Kangen-karyu inhibited adipocyte differentiation and adipogenesis by affecting the transcriptional factor cascade upstream of PPAR $\gamma$, SREBP-1c, FAS, and aP2, possibly resulting in the inhibition of lipid accumulation by inhibiting adipogenesis.

As an experimental model of dyslipidemiaassociated type 2 diabetes mellitus, $d b / d b$ mice are widely used and well-established (19,30). C57BLKS/ $\mathrm{J} d b / d b$ mice develop diabetes due to mutation of the mouse diabetes $(d b)$ gene that encodes a receptor for leptin. The lack of leptin-receptor signaling results in increased food intake in combination with a phenotype of reduced energy expenditure, reminiscent of the neuroendocrine starvation response (31). Consequently, the homozygotes $(d b / d b)$ after birth show unrepressed 
eating behavior, become obese, and, by 3-6 months after birth, develop severe insulin resistance associated with hyperinsulinemia, hyperglycemia, and hypertriglyceridemia. Therefore, in this study, we investigated whether Kangen-karyu ameliorates metabolic disorders including hyperlipidemia, using well-established $d b / d b$ type 2 diabetic mice.

The effects of Kangen-karyu on serum lipid levels such as TG, total cholesterol, HDL cholesterol, LDL/VLDL cholesterol, and NEFA were examined. We found that $d b / d b$ mice showed hyperlipidemia. However, the administration of Kangen-karyu reduced hyperlipidemia through lowering TG, LDL/VLDL cholesterol, and NEFA. Also, to investigate the effects of Kangen-karyu on hepatic damage induced by abnormal lipid synthesis, the lipid contents in the liver of $d b / d b$ mice were also examined. The hepatic content of TG was significantly decreased by the administration of Kangen-karyu. These results mean that Kangenkaryu may inhibit fat deposit or lipid output to blood with the regulation of lipid metabolism such as TG synthesis in type 2 diabetes.

Up-regulation of SREBP-1 was reported in leptinresistant mice, such as $o b / o b$ mice and $\mathrm{FVB}^{d b / d b}$ mice $(32,33)$. In this study, the increase in hepatic SREBP-1 in $d b / d b$ mice was down-regulated by the administration of Kangen-karyu. This was probably related to the inhibition of hepatic TG accumulations. Furthermore, PPARs, with three isoforms $(\alpha, \delta$, and $\gamma)$, are also involved in the longterm regulation of lipid metabolism, and their activity is modulated by endogenous lipid-derived ligands. When PPAR $\alpha$ is activated, it promotes fatty acid oxidation, ketone body synthesis, and glucose sparing (34). In our study, hepatic PPAR $\alpha$ was decreased in $d b / d b$ mice; it was increased slightly, but not significantly, by Kangenkaryu administration. However, we found that Kangenkaryu exhibits a significant effect on regulation of SREBP-1. These results suggest that Kangen-karyu has an ameliorating effect on dyslipidemia in type 2 diabetic mice through the regulation of impaired hepatic SREBPs.

It is well known that SREBP-1 primarily controls genes involved in fatty acid synthesis (29). These include the genes for ACC and FAS in the fatty acid synthesis pathway (35). Type 2 diabetes is associated with increased de novo lipogenesis, decreased plasma fatty acid oxidation, and increased fatty acid flux from peripheral tissues to the liver (36). Therefore, we examined the effect of Kangen-karyu on regulating lipogenic enzyme genes such as ACC and FAS involved in fatty acid synthesis in the $d b / d b$ mice liver using a real-time quantitative PCR technique. Our results strongly suggest that Kangen-karyu mediates the TGlowering action by reducing the expression of ACC and FAS, thereby inhibiting fatty acid synthesis in type 2 diabetic mice.

Another finding noted in this study was that Kangenkaryu treatment improved impaired liver function in type 2 diabetic mice. Elevated serum levels of ALT and AST usually indicate hepatocyte damage (37). In $d b / d b$ mice, serum ALT and AST were notably increased, but Kangen-karyu treatment showed a tendency to reduce these parameters, suggesting that Kangen-karyu might play an important role in improving liver function.

Thiazolidinediones and fibrate drugs are the most commonly used medications for type 2 diabetes mellitus, hyperlipidemia, and insulin resistance. They bind to and activate PPARs, which results in the upregulation of several genes involved in glucose and lipid metabolism (38). PPARs are currently viewed as potential therapeutic targets for the treatment of diabetes and dyslipidemia. PPAR $\gamma$, predominantly expressed in adipose tissue and macrophages (39), affects genes involved in lipid synthesis and storage, and glucose homeostasis. PPAR $\gamma$ agonists, such as thiazolidinediones, control lipid metabolism and insulin sensitivity. However, several concerns such as body weight gain associated with an excess increase of fat mass arise in type 2 diabetes mellitus patients (40). Accumulating evidence indicates that the activation of PPAR $\alpha$ stimulates lipid consumption by enhancing the expression of fatty acid oxidation genes, resulting in the amelioration of hyperlipidemia (41). PPAR $\alpha$ agonists, such as fenofibrate used for the treatment of hyperlipidemia and reducing cardiovascular disease, have a potent effect on reducing plasma TG (42). Because of these distinct metabolic effects of PPAR $\alpha$ and PPAR $\gamma$ agonists on insulin sensitivity and lipid metabolism, new drug development has focused on dual PPARs which possess PPAR $\gamma$ as well as PPAR $\alpha$ activity. In this study, we initially assessed the protective effects of Kangen-karyu against type 2 diabetes by investigating specific markers in the serum and hepatic tissue of $d b / d b$ mice, thereby highlighting Kangen-karyu as a promising anti-lipotoxic agent for type 2 diabetes.

\section{References}

1. Alberti KGMM, Eckel RH, Grundy SM, Zimmet PZ, Cleeman JI, Donato KA, Fruchart JC, James WPT, Loria $\mathrm{CM}$, Smith Jr. SC. Harmonizing the metabolic syndrome: a joint interim statement of the International Diabetes Federation Task Force on Epidemiology and Prevention; National Heart, Lung, and Blood Institute; American Heart Association; World Heart Federation; International Atherosclerosis Society; and International Association for the Study of Obesity. Circulation. 2009; 120:1640-1645.

2. Eckel RH, Albert KG, Grundy SM, Zimmet PZ. The metabolic syndrome. Lancet. 2010; 375:181-183.

3. Phillips C, Lopez-Miranda J, Perez-Jimenez F, McManus R, Roche HM. Genetic and nutrient determinants of the metabolic syndrome. Curr Opin Cardiol. 2006; 21:185193.

4. Gregor MF, Hotamisligil GS. Inflammatory mechanisms in obesity. Annu Rev Immunol. 2011; 29:415-445.

5. Hwang JT, Park IJ, Shin JI, Lee YK, Lee SK, Baik 
HW, Ha J, Park OJ. Genistein, EGCG, and capsaicin inhibit adipocyte differentiation process via activating AMP-activated protein kinase. Biochem Biophys Res Commun. 2005; 338:694-699.

6. Shepherd PR, Gnudi L, Tozzo E, Yang H, Leach F, Kahn BB. Adipose cell hyperplasia and enhanced glucose disposal in transgenic mice overexpressing GLUT4 selectively in adipose tissue. J Biol Chem. 1993; 268:22243-22246.

7. Sorisky A. From preadipocyte to adipocyte: Differentiation-directed signals of insulin from the cell surface to the nucleus. Crit Rev Clin Lab Sci. 1999; 36:1-34.

8. Lottenberg AM, Afonso Mda S, Lavrador MS, Machado RM, Nakandakare ER. The role of dietary fatty acids in the pathology of metabolic syndrome. J Nutr Biochem. 2012; 23:1027-1040.

9. Hwang HS, Kim SH, Yoo YG, Chu YS, Shon YH, Nam KS, Yun JW. Inhibitory effect of deep-sea water on differentiation of 3T3-L1 adipocytes. Mar Biotechnol. 2009; 11:161-168.

10. Hataguchi Y, Tai H, Nakajima H, Kimata H. Drinking deep-sea water restores mineral imbalance in atopic eczema/dermatitis syndrome. Eur J Clin Nutr. 2005; 59:1093-1096.

11. Bubela T, Boon H, Caulfield T. Herbal remedy clinical trials in the media: A comparison with the coverage of conventional pharmaceuticals. BMC Med. 2008; 6:1-14.

12. Takahashi M, Sugaya K, Kubota K. Kangenkaryu prevents the decrease of cholinergic markers following the nucleus basalis magnocellularis lesion. Japan J Pharmacol. 1992; 60:307-310.

13. Gao M, Ikeda K, Noguchi T, Mori K, Yamori Y. Studies on preventive effect of 'Kangenkaryu', Chinese herbal medicine, on stroke in SHR-SP. J Trad Med. 2001; 18:245-250.

14. Makino T, Wakushima H, Okamoto T, Okukubo Y, Saito K, Kano Y. Effects of Kangen-karyu on coagulation system and platelet aggregation in mice. Biol Pharm Bull. 2002; 25:523-525.

15. Cho EJ, Okamoto T, Yokozawa T. Therapeutic efficacy of Kangen-karyu against $\mathrm{H}_{2} \mathrm{O}_{2}$-induced premature senescence. J Pharm Pharmacol. 2008; 60:1537-1544.

16. Yokozawa T, Cho EJ, Sasaki S, Satoh A, Okamoto T, Sei Y. The protective role of Chinese prescription Kangenkaryu extract on diet-induced hypercholesterolemia in rats. Biol Pharm Bull. 2006; 29:760-765.

17. Yokozawa T, Kim HJ, Yamabe N, Okamoto T, Cho EJ. The protective role of Kangen-karyu against fructoseinduced metabolic syndrome in a rat model. J Pharm Pharmacol. 2007; 59:1271-1278.

18. Kim HY, Okamoto T, Yokozawa T. Beneficial effects of Chinese prescription Kangen-karyu on diabetes associated with hyperlipidemia, advanced glycation endproducts, and oxidative stress in streptozotocin-induced diabetic rats. J Ethnopharmacol. 2009; 124:263-269.

19. Hummel KP, Dickie MM, Coleman DL. Diabetes, a new mutation in the mouse. Science. 1966; 153:1127-1128.

20. Park CW, Kim HW, Ko SH, Lim JH, Ryu GR, Chung HW, Han SW, Shin SJ, Bang BK, Breyer MD, Chang YS. Long-term treatment of glucagon-like peptide-1 analog exendin-4 ameliorates diabetic nephropathy through improving metabolic anomalies in $d b / d b$ mice. J Am Soc Nephrol. 2007; 18:1227-1238.

21. Orland MJ, Permutt MA. Quantitative analysis of pancreatic proinsulin mRNA in genetically diabetic $(d b /$ db) mice. Diabetes. 1987; 36:341-347.

22. Folch J, Lees M, Sloane Stanley GH. A simple method for the isolation and purification of total lipids from animal tissues. J Biol Chem. 1957; 226:497-509.

23. Farrigan C, Pang K. Obesity market overview. Nat Rev Drug Discov. 2002; 1:257-258.

24. Frühbeck G, Gómez-Ambrosi J, Muruzábal FJ, Burrell MA. The adipocyte: A model for integration of endocrine and metabolic signaling in energy metabolism regulation. Am J Physiol Endocrinol Metab. 2001; 280:E827-E847.

25. Kershaw EE, Flier JS. Adipose tissue as an endocrine organ. J Clin Endocrinol Metab. 2004; 89:2548-2556.

26. Zimmet P, Magliano D, Matsuzawa Y, Alberti G, Shaw J. The metabolic syndrome: A global public health problem and a new definition. J Atheroscler Thromb. 2005; 12:295-300

27. Farmer SR. Transcriptional control of adipocyte formation. Cell Metab. 2006; 4:263-273.

28. Shimano H. SREBPs: physiology and pathophysiology of the SREBP family. FEBS J. 2009; 276:616-621.

29. Yahagi N, Shimano H, Hasty AH, et al. Absence of sterol regulatory element-binding protein-1 (SREBP-1) ameliorates fatty livers but not obesity or insulin resistance in $L e p^{o b} / L_{e p}^{o b}$ mice. J Biol Chem. 2002; 277:19353-19357.

30. Kaku K, Province M, Permutt MA. Genetic analysis of obesity-induced diabetes associated with a limited capacity to synthesize insulin in C57BL/KS mice: evidence for polygenic control. Diagetologia. 1989; 32:636-643.

31. Münzbery H, Myers MG. Molecular and anatomical determinants of central leptin resistance. Nat Neurosci. 2005; 8:566-570.

32. Tobe K, Suzuki R, Aoyama M, Yamauchi T, Kamon J, Kubota N, Terauchi Y, Matsui J, Akanuma Y, Kimura S, Tanaka J, Abe M, Ohsumi J, Nagai R, Kadowaki T. Increased expression of the sterol regulatory elementbinding protein-1 gene in insulin receptor substrate- $2^{-/-}$ mouse liver. J Biol Chem. 2001; 276:38337-38340.

33. Wang Z, Jiang T, Li J, Proctor G, McManaman JL, Lucia S, Chua S, Levi M. Regulation of renal lipid metabolism, lipid accumulation, and glomerulosclerosis in $\mathrm{FVB}^{d b / d b}$ mice with type 2 diabetes. Diabetes. 2005; 54:2328-2335.

34. Ferré P. The biology of peroxisome proliferator-activated receptors. Relationship with lipid metabolism and insulin sensitivity. Diabetes. 2004; 53:S43-S50.

35. Girard J, Perdereau D, Foufelle F, Prip-Buus C, Ferré P. Regulation of lipogenic enzyme gene expression by nutrients and hormones. FASEB J. 1994; 8:36-42.

36. Nestel P, Goldrick B. Obesity: Changes in lipid metabolism and the role of insulin. Clin Endocrinol Metab. 1976; 5:313-335.

37. Amacher DE. Serum transaminase elevations as indicators of hepatic injury following the administration of drugs. Regul Toxicol Pharmacol. 1998; 27:119-130.

38. Michalik L, Auwerx J, Berger JP, et al. International union of pharmacology. LXI. Peroxisome proliferatoractivated receptors. Pharmacol Rev. 2006; 58:726-741.

39. Vidal-Puig AJ, Considine RV, Jimenez-Liñan M, Werman A, Pories WJ, Caro JF. Peroxisome proliferator-activated receptor gene expression in human tissues. J Clin Invest. 1997; 99:2416-2422.

40. Fonseca V. Effect of thiazolidinediones on body weight in patients with diabetes mellitus. Am J Med. 2003; 115:42S-48S. 
41. Bünger M, Hooiveld GJEJ, Kersten S, Müller M. Exploration of PPAR functions by microarray technology: A paradigm for nutrigenomics. Biochim Biophys Acta. 2007; 1771:1046-1064.

42. Bajaj M, Suraamornkul S, Hardies LJ, Glass L, Musi N, DeFronzo RA. Effects of peroxisome proliferator- activated receptor (PPAR)- $\alpha$ and PPAR- $\gamma$ agonists on glucose and lipid metabolism in patients with type 2 diabetes mellitus. Diabetologia. 2007; 50:1723-1731.

(Received May 7, 2014; Revised June 16, 2014; Accepted June 20, 2014) 